\title{
Qualidade tecnológica de grãos de cultivares de feijão-comum na safra das águas
}

\section{Grain technological quality of common beans cultivars in the rainy crop season}

\author{
Dâmiany Pádua Oliveira ${ }^{1 *}$; Neiva Maria Batista Vieira ${ }^{2}$; Henrique Cézar Souza ${ }^{3}$; \\ Augusto Ramalho de Morais ${ }^{4}$; Joelma Pereira ${ }^{5}$; Messias José Bastos de Andrade ${ }^{6}$
}

\section{Resumo}

O feijão-comum (Phaseolus vulgaris L.) é um alimento rico em nutrientes e a principal fonte proteica na dieta dos brasileiros, principalmente da população de baixa renda. $\mathrm{O}$ tipo de grão mais consumido no Brasil é o tipo carioca, também o mais produzido. Recentemente, programas de melhoramento têm disponibilizado novas cultivares, com grãos de outros grupos comerciais, mas a viabilização da sua adoção pelos produtores requer, além da adequação dos atuais sistemas de produção, avaliações da qualidade tecnológica dos grãos produzidos. O objetivo do trabalho foi então avaliar a qualidade tecnológica de grãos de cultivares de diferentes grupos comerciais de feijão-comum colhidos na safra das águas, que geralmente produz grãos de qualidade inferior. Para tanto, os grãos obtidos foram submetidos a diferentes análises laboratoriais, assumindo-se um delineamento em blocos casualizados com cinco tratamentos (cultivares BRS Radiante, Ouro Vermelho, BRS MG Talismã, BRS Supremo e Bolinha) e cinco repetições. A qualidade tecnológica de grãos de feijão-comum varia com a cultivar, exceto em relação a porcentagem de embebição de água pelos grãos após o cozimento e porcentagem de grãos inteiros. A cultivar BRS MG Talismã, do grupo carioca, apresenta menor tempo médio de cocção, menor condutividade elétrica e maior taxa de expansão volumétrica. A cultivar Bolinha, do grupo amarelo, demanda maior tempo médio de cozimento.

Palavras-chave: Qualidade física, qualidade química, tempo de cozimento, Phaseolus vulgaris

\begin{abstract}
Common bean (Phaseolus vulgaris L.) is a nutrient-rich food and the main protein source in the Brazilians' diet, chiefly of the low income population. The sort of bean most consumed in Brazil is the carioca and it is also the most produced. Recently, breeding programs have made new cultivars available with beans of other commercial groups, but the enablement of its adoption by the farmers demands, in addition to the adequacy of the current production systems, evaluations of the technological quality of the beans produced. The purpose of the work was evaluating the technological quality of beans of cultivars of different commercial groups of bean harvested in the rainy season crop, which in general produces lower quality beans. For this purpose, the beans obtained were submitted to different laboratory analyses, adopting the randomized block design with five treatments (cultivars BRS Radiante, Ouro
\end{abstract}

\footnotetext{
1 Eng ${ }^{\mathrm{a}} \mathrm{Agr}^{\mathrm{a}}$, Doutoranda em Agronomia/Fitotecnia, Universidade Federal de Lavras, UFLA, Lavras, MG. E-mail: damy_agro84@ hotmail.com

2 Prof ${ }^{a}$, Dsc., Instituto Federal do Sul de Minas, Machado, MG. E-mail: neiva@eafmachado.gov.br

3 Graduando em Agronomia, UFLA, Lavras, MG. E-mail: henriquecezar_2@hotmail.com

4 Prof. Associado, Dsc., Dept ${ }^{\circ}$. de Ciência Exatas, UFLA, Lavras, MG. E-mail: armorais@ufla.br

5 Prof $^{\text {a }}$ Associada II, Dsc., Dept ${ }^{\mathrm{o}}$. de Ciência dos Alimentos, UFLA, Lavras, MG. E-mail: joper@ufla.br

6 Prof. Associado III, Dsc., Dept ${ }^{\circ}$. de Agricultura, UFLA, Lavras, MG. E-mail: mandrade@dag.ufla.br

Autor para correspondência
} 
Vermelho, BRS MG Talismã, BRS Supremo and Bolinha) and five replicates. The technological quality of bean beans range according to the cultivar, except in relation to the water imbibition percentage by the beans after cooking and percentage of whole beans. Cultivar BRS MG Talismã, of the carioca group, present shorter cooking time, less electric conductivity and higher volumetric expansion rate. Cultivar Bolinha, of yellow group, demand longer cooking average time.

Key words: Physical quality, chemical quality, cooking time, Phaseolus vulgaris

\section{Introdução}

O feijão é um alimento com significativa composição nutritiva e relativamente balanceado, que tem grande aceitação nos mais diferentes hábitos alimentares. Nos países em que o consumo de proteína animal é limitado, constitui a principal fonte de proteína de grande parcela da população (RIOS, ABREU; CORRÊA, 2003). No Brasil, além de ser uma cultura de expressão sócio-econômica, se apresenta como fonte alimentar com menor custo de proteína em relação a produtos de origem animal (MESQUITA et al., 2007).

Embora ainda haja certa diversidade no consumo, atualmente o mercado de feijão Phaseolus no Brasil se caracteriza por grande preferência pelo tipo comercial carioca, o que geralmente resulta em menores preços no atacado e em grande exigência de qualidade, nem sempre conseguida pelo produtor, que acaba comercializando o seu produto com deságio. A entrada de cultivares de feijão de outros grupos comerciais no mercado pode representar para o produtor, portanto, uma forma de agregar valor ao produto final, apenas com a escolha de nova cultivar para a semeadura.

Os programas de melhoramento de feijão têm disponibilizado novas cultivares de outros grupos comerciais, mas sua efetiva adoção pelos produtores requer, além da adequação dos sistemas de produção (ALVES et al., 2009), avaliações sobre a qualidade tecnológica dos grãos, ou seja, sobre a qualidade física, química e sensorial dessa leguminosa (EMBRAPA, 2012).

Os consumidores prezam por grãos com melhor aptidão culinária, que reúnam aspectos positivos, tais como facilidade de embebição, menor tempo de cocção, alta expansão volumétrica do grão e grãos inteiros após cozimento. Portanto, cultivares com maiores taxas de hidratação e menor tempo de cozimento, características tecnológicas positivamente correlacionadas (GARCIA-VELA; STANLEY, 1989; RESENDE et al., 2008), são desejáveis, significando economia de energia e de capital. Além do benefício econômico, a rápida cocção diminui a exposição da membrana estrutural do grão a mudanças em nível celular, evitando, desse modo, que haja perda de nutrientes para a água de maceração (WASSIMI; HOSFI; UBERSAX, 1988). É conveniente ressaltar que todas as características citadas podem ser influenciadas pela constituição genética do grão e pelas condições ambientais de sua produção, bem como pela interação entre ambos, e são importantes na aceitação de uma cultivar para consumo.

Assim, o objetivo do presente trabalho foi avaliar a qualidade tecnológica de grãos de cultivares de diferentes grupos comerciais de feijão produzidos na safra das águas, que geralmente produz grãos de qualidade inferior no Sul de Minas Gerais.

\section{Material e Métodos}

Para a caracterização da qualidade tecnológica dos grãos, cinco cultivares de feijoeiro (Tabela 1) foram cultivadas na safra das águas 2008/2009, em área experimental do Departamento de Agricultura da Universidade Federal de Lavras (UFLA), Lavras-MG, situada a $21^{\circ} 14^{\prime} \mathrm{S}, 45^{\circ} 00^{\prime} \mathrm{W}$ e $910 \mathrm{~m}$ de altitude (ASSIS et al., 2012). Análise química prévia de amostra do solo (0 a $20 \mathrm{~cm}$ de profundidade), um Latossolo Vermelho distroférrico típico (EMBRAPA, 1999), forneceu os resultados apresentados na Tabela 2 .

O preparo do solo constou de uma aração e duas 
gradagens e a calagem havia sido realizada na safra anterior. A adubação de semeadura foi realizada com $400 \mathrm{~kg} \mathrm{ha}^{-1}$ do fertilizante formulado 8-28-16 e, em cobertura, foram aplicados $30 \mathrm{~kg}$ de $\mathrm{N}$ fonte ureia, no estádio $\mathrm{V}_{4}$ do ciclo do feijoeiro, ou seja, quando as plantas apresentavam a terceira folha trifoliolada desenvolvida (FERNANDEZ; GEPTS; LÓPEZ, 1985).
$\mathrm{Na}$ véspera da semeadura, as sementes foram tratadas com Vitavax-Thiram ${ }^{\circledR} 200$ SC na dose de 2,5 $\mathrm{mL} \mathrm{kg}^{-1}$ de semente. A semeadura mecânica foi realizada no dia 25 de novembro, adotandose a densidade média de 16 sementes por metro e espaçamento de $0,5 \mathrm{~m}$ entre fileiras. Cada cultivar foi semeada em área aproximada de $500 \mathrm{~m}^{2}$. Na colheita foram desprezadas duas linhas externas em cada lateral.

Tabela 1. Cultivares estudadas e suas principais características.

\begin{tabular}{|c|c|c|c|c|c|}
\hline Característica & $\begin{array}{c}\text { BRS } \\
\text { Radiante }^{1}\end{array}$ & Ouro Vermelho ${ }^{1}$ & $\begin{array}{c}\text { BRS MG } \\
\text { Talisma }^{1}\end{array}$ & $\begin{array}{c}\text { BRS } \\
\text { Supremo }^{2}\end{array}$ & Bolinha $^{3}$ \\
\hline Grupo comercial & Outros & Outros & Carioca & Preto & Outros \\
\hline Tipo de grão & rajado & vermelho & carioca & preto & amarelo \\
\hline Hábito de crescimento & tipo I & tipo II/III & tipo III & tipo II & tipo II \\
\hline Peso de 100 grãos (g) & $44-45$ & 25 & $26-27$ & 25 & $31-35$ \\
\hline Ciclo & precoce & normal & médio & normal & normal \\
\hline
\end{tabular}

${ }^{1}$ Ramalho e Abreu (2006), ${ }^{2}$ Melo et al. (2005) e ${ }^{3}$ Alves et al. (2009).

Tabela 2. Análise química de amostra de material do solo utilizado ( 0 a $20 \mathrm{~cm}$ de profundidade $)^{*}$.

\begin{tabular}{|c|c|c|c|}
\hline Características & Valores & Características & Valores \\
\hline $\mathrm{pH}$ em $\mathrm{H}_{2} \mathrm{O}$ & $5,4 \mathrm{AcM}$ & 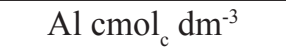 & $0,5 \mathrm{Ba}$ \\
\hline $\mathrm{P}\left(\right.$ Mehlich 1) $\mathrm{mg} \mathrm{dm}^{-3}$ & $1,2 \mathrm{MBa}$ & $\mathrm{H}+\mathrm{AL} \mathrm{cmol} \mathrm{dm}^{-3}$ & $4,0 \mathrm{~A}$ \\
\hline $\mathrm{K}\left(\right.$ Mehlich 1) $\mathrm{mg} \mathrm{dm}^{-3}$ & $62,0 \mathrm{M}$ & $\mathrm{SB} \mathrm{cmol}_{\mathrm{c}} \mathrm{dm}^{-3}$ & $1,8 \mathrm{Ba}$ \\
\hline Ca cmolc dm ${ }^{-3}$ & $1,2 \mathrm{Ba}$ & Mat. Org. dag kg- ${ }^{1}$ & $2,6 \mathrm{M}$ \\
\hline Mg cmolc dm ${ }^{-3}$ & $0,4 \mathrm{MBa}$ & $\mathrm{V}(\%)$ & $30,6 \mathrm{Ba}$ \\
\hline
\end{tabular}

* Análises realizadas no Laboratório de Fertilidade do Solo do Departamento de Ciência do Solo da UFLA e interpretação de acordo com Alvarez e Ribeiro (1999). AcM = acidez média, $\mathrm{A}=$ alto teor, $\mathrm{M}=$ teor médio, $\mathrm{Ba}=$ teor baixo e $\mathrm{MBa}=$ teor muito baixo. Fonte: Elaboração dos autores.

Os tratos culturais foram os normalmente dispensados à cultura na região. As plantas daninhas foram controladas por meio de aplicação de herbicida Robust (fluazifop-butil + fomesafen) na dose de $0,8 \mathrm{~L} \mathrm{ha}^{-1}$, com gramíneas no estádio de 2-5 perfilhos e as latifoliadas no estádio de 2-4 folhas. Por se tratar de época de boa precipitação, não houve irrigação.

$\mathrm{O}$ arranquio manual das plantas foi realizado em fevereiro, à medida que cada cultivar alcançava a sua maturação. Em seguida, procedeu-se à trilha manual e abanação em peneiras, sendo a secagem realizada ao sol, monitorada permanentemente para que os grãos pudessem alcançar umidade próxima a $13 \%$.

As determinações para a qualidade tecnológica dos grãos foram realizadas nas dependências do Laboratório de Grãos, Raízes e Tubérculos Laboratório de Produtos Vegetais e Laboratório de Pós-Colheita do Departamento de Ciência dos Alimentos (DCA) e do Laboratório de Análise de Sementes do Departamento de Agricultura, todos da Universidade Federal de Lavras. 
Avaliou-se a porcentagem de embebição antes (PEANC) e após o cozimento (PEAPC), por meio dos métodos de Garcia-Vela e Stanley (1989) e de Plhak, Caldwell e Staanley (1989), modificados como a seguir. Foram amostrados aproximadamente $30 \mathrm{~g}$ de grãos uniformes e inteiros obtendo-se, desse modo, a massa seca dos grãos (MS) no estádio inicial do procedimento analítico. Os grãos foram embebidos em $100 \mathrm{~mL}$ de água destilada, em béquer de $250 \mathrm{~mL}$, por 16 horas, à temperatura ambiente. Para PEANC, após esse período, os grãos foram retirados e rapidamente secos com papel toalha e, em seguida pesados, obtendo-se a massa dos grãos úmidos (MU) e a porcentagem de embebição, determinada pela fórmula: PEANC $=[(M U-M S) / M S] \times 100$. Para PEAPC, após as 16 horas de embebição os $30 \mathrm{~g}$ de grãos foram aquecidos em chapa aquecedora elétrica por uma hora após o início da fervura, com reposição da água evaporada, quando necessário. Os grãos (inteiros e fragmentados) foram drenados e, então, pesados, obtendo-se a massa úmida após cozimento (MUc). A PEAPC foi determinada pela fórmula: $P E A P C=$ $[(M U c-M S) / M S] \times 100, \mathrm{em} \%$.

Da amostra proveniente da PEAPC foi obtida a porcentagem de grãos inteiros após cozimento (PGI). Os grãos, após cozimento, foram contabilizados em sua totalidade (TG) e separados em duas porções: inteiros (GI) e partidos (GP). A partir dessa contagem, calculou-se então a PGI, pela fórmula: $P G I=[(T G-G P) / T G] \times 100, \mathrm{em} \%$.

Foi também determinada a taxa de expansão volumétrica dos grãos após cozimento (TEV), de acordo com adaptações no método proposto por Martin-Cabrejas et al. (1997), com operações semelhantes às adotadas para a PEAPC, acrescidas, após uma hora sob fervura, de uma pré-lavagem com água destilada e leve secagem com papel-toalha. Em seguida, as amostras foram colocadas em uma proveta com capacidade para $500 \mathrm{~mL}$, contendo $250 \mathrm{~mL}$ de água destilada e medido o volume deslocado de água (VD) e a taxa de expansão volumétrica, determinada pela fórmula: $E V=(M S / V D)$, em $g \mathrm{~mL}^{-1}$.
O tempo médio de cocção (TMC) foi determinado pelo Cozedor de Mattson. De acordo com o método de Sartori (1982) modificado por Proctor e Watts (1987), foram amostrados $30 \mathrm{~g}$ de grãos uniformes e inteiros. Os grãos foram colocados em embebição em $100 \mathrm{~mL}$ de água destilada, por 16 horas, à temperatura ambiente. Vinte e cinco grãos, tomados aleatoriamente, foram colocados individualmente em uma cavidade do aparelho de Mattson e sob uma vareta de metal de $90 \mathrm{~g}$ e 1,48 $\mathrm{mm}$ de diâmetro de ponta. Inicialmente, $1000 \mathrm{~mL}$ de água destilada foram aquecidos até a fervura em um recipiente de alumínio com capacidade de 3000 $\mathrm{mL}$ no qual, por último, foi colocado o Cozedor já preparado com os grãos, cronometrando-se o tempo de cozimento das amostras, em minutos, pela queda da décima terceira vareta, perfurando-se, deste modo, treze grãos. Conforme a necessidade, acrescentou-se água fervente para reposição.

O teste de condutividade elétrica (CE) foi o descrito por Vieira (1994). Foram utilizadas quatro sub-amostras de 50 sementes, por cultivar. Cada sub-amostra foi pesada e colocada em copos plásticos contendo $75 \mathrm{~mL}$ de água destilada e mantidas a $25^{\circ} \mathrm{C}$ por 24 horas. A condutividade elétrica da solução foi medida com o uso de condutivímetro marca Digimed, modelo CD-21, com ajuste para compensação da temperatura e eletrodo com constante da célula de $1 \mu \mathrm{S} \mathrm{cm}^{-1}$. Antes de se realizar as leituras, o aparelho foi calibrado com uma solução-padrão de cloreto de sódio, de condutividade elétrica conhecida, à temperatura de $25^{\circ} \mathrm{C}$ e as amostras tiveram suas soluções agitadas para a determinação da condutividade elétrica. Ao fim, os valores obtidos na leitura (Le), foram divididos pelo peso da amostra (g), de acordo com a expressão $C E=(L e / M S)$, em $\mu \mathrm{S} \mathrm{cm}^{-1} \mathrm{~g}^{-1}$.

Todos os dados foram submetidos à análise de variância assumindo-se um delineamento em blocos casualizados com cinco tratamentos (cultivares) e cinco repetições. Quando houve efeito significativo de cultivar, foi utilizado o teste de Scott-Knott, conforme Ramalho, Ferreira e Oliveira (2005) 
para agrupamento de tratamentos em semelhantes e diferentes. Para as análises utilizou-se o software estatístico SISVAR versão 4.0 (FERREIRA, 2011).

\section{Resultados e Discussão}

$\mathrm{Na}$ análise de variância (Tabela 3) os valores obtidos para o coeficiente de variação permitem afirmar que houve boa precisão experimental e, com exceção da PEAPC e PGI, todas as características foram influenciadas pelo fator cultivar.

De fato, os valores médios de PEAPC e PGI apresentaram pequena variação e seus valores médios foram $104,77 \%$ e $98,46 \%$, respectivamente (Tabela 4). No caso do PEAPC, o valor indica que os grãos embeberam, em média, quantidade de água equivalente ao seu peso. Por outro lado, o valor médio do PGI indica que menos de $2 \%$ dos grãos se romperam durante o cozimento, proporcionando mais de 98\% de grãos inteiros.

Com relação à porcentagem de embebição antes do cozimento (PEANC), o teste de Scott-Knott permitiu a identificação de três grupos de cultivares. A cv. Radiante, a de maior tamanho de grãos, foi a que apresentou maior porcentagem de embebição, acima de 94\%. As cultivares Ouro Vermelho, Talismã e Supremo apresentaram embebição intermediária, em torno de 91\%, enquanto a cv. Bolinha, de grãos amarelos, foi a que menos embebeu água antes do cozimento (Tabela 4).

Tabela 3. Resumo da análise de variância com fontes de variação, número de graus de liberdade e quadrados médios dos dados referentes a porcentagem de embebição antes (PEANC) e após cozimento (PEAPC) e de grãos inteiros (PGI) após o cozimento, taxa de expansão volumétrica (TEV), tempo médio de cocção (TMC) e condutividade elétrica (CE) de cinco cultivares de feijoeiro, logo após a colheita.

\begin{tabular}{ccccclcc}
\hline FV & GL & PEANC & PEAPC & PGI & TEV & TMC & CE \\
\hline Cultivar & 4 & $18,6255^{* *}$ & 174,4699 & 0,71 & $0,0043^{* *}$ & $27,4610^{* *}$ & $1006,8534^{* *}$ \\
Bloco & 4 & 0,6273 & 49,8896 & 0,05 & 0,0002 & 2,0990 & 249,8099 \\
Erro & 16 & 1,1059 & 72,6189 & 1,62 & 0,0004 & 2,3502 & 142,5262 \\
\hline CV $(\%)$ & - & 1,15 & 8,13 & 1,30 & 3,66 & 6,72 & 19,23 \\
\hline
\end{tabular}

** Significativo ao nível de $1 \%$ de probabilidade pelo teste.

Fonte: Elaboração dos autores.

Tabela 4. Valores médios de porcentagem de embebição antes (PEANC) e após cozimento (PEAPC) e de grãos inteiros (PGI) após o cozimento, taxa de expansão volumétrica (TEV), tempo médio de cocção (TMC) e condutividade elétrica (CE) de cinco cultivares de feijoeiro, logo após a colheita.

\begin{tabular}{|c|c|c|c|c|c|c|}
\hline Cultivares & $\begin{array}{c}\text { PEANC } \\
(\%) \\
\end{array}$ & $\begin{array}{c}\text { PEAPC } \\
(\%) \\
\end{array}$ & \begin{tabular}{|l} 
PGI \\
$(\%)$ \\
\end{tabular} & $\begin{array}{c}\text { TEV } \\
\left(\mathrm{g} \mathrm{mL}^{-1}\right) \\
\end{array}$ & $\begin{array}{c}\text { TMC } \\
\text { (minutos) } \\
\end{array}$ & $\begin{array}{c}C \mathbf{C E} \\
\left(\mu \mathrm{Sm}^{-1} \mathrm{~g}^{-1}\right)\end{array}$ \\
\hline BRS-Radiante & $94,18 \mathrm{a}$ & 100,29 & 98,24 & $0,54 \mathrm{~b}$ & $23,21 \mathrm{~b}$ & $49,89 a$ \\
\hline Ouro Vermelho & $91,71 \mathrm{~b}$ & 109,91 & 98,50 & $0,53 \mathrm{~b}$ & $23,81 \mathrm{~b}$ & $67,89 \mathrm{~b}$ \\
\hline BRS-Talismã & $91,80 \mathrm{~b}$ & 108,71 & 98,44 & $0,60 \mathrm{a}$ & $20,61 \mathrm{a}$ & $45,11 \mathrm{a}$ \\
\hline BRS-Supremo & $90,87 \mathrm{~b}$ & 108,36 & 98,08 & $0,55 \mathrm{~b}$ & $20,41 \mathrm{a}$ & $79,33 \mathrm{~b}$ \\
\hline Bolinha & $88,81 \mathrm{c}$ & 95,58 & 99,07 & $0,59 \mathrm{a}$ & $26,00 \mathrm{c}$ & $68,20 \mathrm{~b}$ \\
\hline Média & 91,47 & 104,77 & 98,46 & 0,56 & 22,80 & 62,08 \\
\hline
\end{tabular}

Médias seguidas pelas mesmas letras pertencem a um mesmo grupo, de acordo com o teste de Scott-Knott ao nível de 5\% de probabilidade.

Fonte: Elaboração dos autores. 
Como todas as cultivares de feijão cozinharam em menos de 30 minutos (Tabela 4), é esperado que tenham aceitação para o consumo (OLIVEIRA, 2008; RODRIGUES et al., 2005b), quando o processamento for realizado logo após a colheita. A cv. Bolinha foi a que apresentou maior tempo de cozimento, seguida pelas cultivares Radiante e Ouro Vermelho. As cvs. Talismã (grupo carioca) e Supremo (grupo preto), foram as que se destacaram, apresentando menor tempo de cozimento, abaixo dos 21 minutos (Tabela 4).

O pior comportamento da cv. Bolinha em relação à PEANC e ao TMC corroboram com os resultados de Stanley e Aguilera (1985), os quais correlacionaram maior tempo de cocção com menor capacidade de penetração de água nos grãos, o que pode ser devido à impermeabilidade do tegumento, resultando em lenta hidratação durante o cozimento. Outra razão para este comportamento pode ser a impermeabilidade dos cotilédones à água, em razão de modificações químicas que ocorrem durante o cozimento (CHIARADIA; GOMES, 1997).

Outros trabalhos também indicam que determinações da capacidade de hidratação dos grãos antes do cozimento podem ser bom indicativo do tempo de cocção, de modo que, maior tempo de hidratação e, ou menor quantidade de água absorvida, levaria a maior tempo de cocção (IBARRAPÉREZ; CASTILHO-ROSALE; CUELLAREVENOR, 1996; RODRIGUES et al., 2005a), o que corroborara com o presente resultado para a cultivar de grão amarelo, a Bolinha. Neste sentido, Andrade e Ramalho (1999) consideram os grãos do grupo amarelo os de pior qualidade culinária, devido à grande espessura e impermeabilidade do seu tegumento, o que os tornam "cascudos" e requerem longo tempo de cozimento, mesmo quando recémcolhidos.

Dalla Corte et al. (2003) e Carbonell, Carvalho e Pereira (2003), entretanto, trabalhando respectivamente com cultivares dos grupos preto e carioca, encontraram baixa correlação entre esses dois caracteres. Esta situação parece também ter ocorrido no presente trabalho com as cvs. Radiante (que apresentou maior PEANCeTMC intermediário) e Supremo e Talismã (com PEANC intermediária e menor TMC). Estes resultados parecem indicar que outros fatores podem estar envolvidos e, possivelmente, atuando simultaneamente.

Com relação à taxa de expansão volumétrica (TEV), verifica-se que as cvs. Talismã e Bolinha se destacaram, com valores de 0,59 e 0,60 , o que corresponde a um aumento de volume da ordem de $60 \%$, enquanto as demais cultivares apresentaram taxas de expansão da ordem de 0,53 a 0,55 (Tabela 4). Para Resende e Corrêa (2007), a TEV expressa a difusão de água no interior dos grãos e, de acordo com Carbonell, Carvalho e Pereira (2003), a expansão volumétrica é uma característica desejável e que influencia na aceitação de uma nova cultivar, a qual deve possuir alta expansão dos grãos após o cozimento. Segundo aqueles autores, bom desempenho de uma cultivar quanto à PEAPC pode ampliar a TEV, fato também sugerido por Resio, Aguerre e Suarez. $(2003$; 2005) e Bello, Tolaba e Suarez (2004). No presente trabalho, as cultivares não diferiram quanto à primeira característica. Considerando que a difusão de água no grão pode ser influenciada negativamente pelo grau de lignificação do grão (MC DOUGALL et al., 1996 apud TEIXEIRA et al., 2005), os resultados dessa característica podem ser um indicativo de menor teor de lignina nos grãos das cvs. Talismã e Bolinha, as de maior TEV.

Os resultados do teste de condutividade elétrica (CE) mostraram que as cvs. Talismã e Radiante foram as que menos drenaram solutos para a solução, com valores inferiores a $50 \mu \mathrm{S} \mathrm{cm} \mathrm{cm}^{-1} \mathrm{~g}^{-1}$. As demais cultivares drenaram mais solutos para a solução teste, com valores de CE entre 67 e $79 \mu \mathrm{S}$ $\mathrm{cm}^{-1} \mathrm{~g}^{-1}$. A cv. Bolinha, a que se apresentou inferior em termos de PEANC e TMC, situou-se entre as cultivares de maior $\mathrm{CE}$, o que significa maior comprometimento da integridade de membranas celulares (KRZYZANOVSKI; FRANÇA NETO, 2001) e, ou teores mais baixos de lignina (PANOBIANCO; VIEIRA, 1996). 


\section{Conclusões}

A qualidade tecnológica de grãos de feijãocomum é influenciada pela cultivar.

A cultivar BRS MG Talismã apresenta o menor tempo médio de cocção, menor condutividade elétrica e maior taxa de expansão volumétrica.

A cultivar Bolinha demanda maior tempo médio de cozimento.

\section{Agradecimentos}

Ao CNPq e FAPEMIG pela concessão de recursos.

\section{Referências}

ALVAREZ V., V. H.; RIBEIRO, A. C. Calagem. In: RIBEIRO, A. C.; GUIMARÃES, P. T. G.; ALVAREZ V., V. H. (Ed). Recomendações para o uso de corretivos e fertilizantes em Minas Gerais. Viçosa, MG: Comissão de Fertilidade do Solo do Estado de Minas Gerais, 1999. p. 43-60.

ALVES, A. F.; ANDRADE, M. J. B.; RODRIGUES, J. R. M.; VIEIRA, N. M. B. Densidades populacionais para cultivares alternativas de feijoeiro no norte de Minas Gerais. Ciência e Agrotecnologia, Lavras, v. 33, n. 6, p. 1495-1502, nov./dez. 2009.

ANDRADE, M. J. B.; RAMALHO, M. A. P. A cultura do feijoeiro-comum no curso de agronomia. Lavras: UFLA, 1999. $180 \mathrm{p}$.

ASSIS, G. A.; ASSIS, F. A.; SCALCO, M. S.; PAROLIN, F. J. T.; FIDELIS, I.; MORAES, J. C.; GUIMARÃES, R. J. Leaf miner incidence in coffee plants under different drip irrigation regimes and planting densities. Pesquisa Agropecuária Brasileira, Brasília, v. 47, n. 2, p. 157-162, fev. 2012.

BELLO, M.; TOLABA, M. P.; SUAREZ, C. Factors affecting water uptake of ricegrain during soaking. Food Science and Technology, Zürich, v. 37, n. 8, p. 811-816, dec. 2004.

CARBONELL, S. A. M.; CARVALHO, R. L.; PEREIRA, V. R. Qualidade tecnológica de grãos de genótipos de feijoeiro cultivados em diferentes ambientes. Bragantia, Campinas, v. 62, n. 3, p. 369-379, 2003.

CHIARADIA, A. C. N.; GOMES, J. C. Feijão: química, nutrição e tecnologia. Viçosa, MG: UFV, 1997. 180 p.
DALLA CORTE, A.; MODA-CIRINO, V.; SCHOLZ, M. B. S.; DESTRO, D. Environment effect on grain quality in early common bean cultivars and lines. Crop Breeding and Applied Biotechnology, Londrina, v. 3, n. 3, p. 193202, 2003.

EMPRESA BRASILEIRA DE PESQUISA AGROPECUÁRIA - EMBRAPA. Centro Nacional de Pesquisa de Solos. Sistema brasileiro de classificação de solos. Brasília: EMBRAPA Produção da Informação, 1999. $412 \mathrm{p}$.

Qualidade tecnológica dos grãos- feijãocaupi. 2012. Disponível em: <http://www.agencia. cnptia.embrapa.br/gestor/feijao-caupi/arvore/ CONTAG01_8_510200683535.html>. Acesso em: 18 jun. 2012.

FERNANDEZ, F.; GEPTS, P.; LÓPEZ, M. Etapas de desarollo em La planta de frijol. In: LÓPEZ, M.; FERNANDEZ, F.; SCHOOWHOVEN, A. V. Frijol, investigación y producción. Colombia: CIAT, 1985. p. 61-80.

FERREIRA, D. F. SISVAR: a computer statistical analysis system. Ciência e Agrotecnologia, Lavras, v. 35, n. 6, p. 1039-1042, 2011.

GARCIA-VELA, L. A.; STANLEY, D. W. Water-holding capacity in hard-to-cook bean (Phaseolus vulgaris L.): effect of $\mathrm{pH}$ and ionic strength. Journal of Food Science, Chicago, v. 54, n. 4, p. 1080-1081, july 1989.

IBARRA-PÉREZ, F. J.; CASTILHO-ROSALES, A.; CUELLAR-EVENOR, I. Treshing effect on cooking time in commercial beans cultivars from the semiarid highlands of Mexico. Bean Improvement Cooperative, Cali, v. 39, p. 264- 265, feb. 1996.

KRZYZANOVSKI, F. C.; FRANÇA NETO, J. B. Vigor de sementes. Informativo Abrates, Londrina, v. 11, n. 3, p. 81-84, sept. 2001.

MARTIN-CABREJAS, M. A.; ESTEBAN, R. M.; PEREZ, P.; MAINA, G.; WALDRON, K. W. Changes in physicochemical properties of dry beans (Phaseolus vulgaris L.) during long-term storage. Journal of Agricultural and Food Chemistry, Washington, v. 45, n. 8, p. 3223-3227, aug. 1997.

MELO, L. C.; FARIA, L. C.; DEL PELOSO, M. J.; COSTA, J. G. C.; RAVA, C.A.; LEMES, G. C.; CABRERA DIAZ, J. L.; ABREU, A. F. B.; ZIMMERMANN, F. J. P. Adaptabilidade e estabilidade de produção da cultivar BRS Supremo em diferentes regiões brasileiras. Santo Antônio de Goiás: Embrapa Arroz e Feijão, 2005. 4 p. (Embrapa Arroz e Feijão. Comunicado técnico, 104).

MESQUITA, F. R.; CORRÊA, A. D.; ABREU, C. M. P.; LIMA, R. A. Z.; ABREU, A. F. B. Linhagens de 
feijão (phaseolus vulgaris 1.): composição química e digestibilidade proteica. Ciência e Agrotecnologia, Lavras, v. 31, n. 4, p. 1114-1121, jul./ago. 2007.

OLIVEIRA, V. R. Análise físico-química, microbiológica e sensorial de cultivares de feijão. 2008. Tese (Doutorado em Agronomia/Produção Vegetal) - Universidade Federal de Santa Maria, Santa Maria.

PANOBIANCO, M.; VIEIRA, R. D. Electrical conductivity of soybean soaked seeds: I effect of genotype. Pesquisa Agropecuária Brasileira, Brasília, v. 31, n. 9, p. 621-627, set. 1996.

PLHAK, L. C.; CALDWELL, K. B.; STANLEY, D. W. Comparison of methods used to characterize water imbibition in hard-to-cook beans. Journal of Food Science, Chicago, v. 54, n. 3, p. 326-336, may 1989.

PROCTOR, J. R.; WATTS, B. M. Development of a modified Mattson bean cooker procedure based on sensory panel cookability evaluation. Canadian Institute of Food Science and Technology Journal, Aplle Hill, v. 20, n. 1, p. 9-14, 1987.

RAMALHO, M. A. P.; ABREU, A. F. B. Cultivares. In: VIEIRA, C.; PAULA JÚNIOR, T. J.; BORÉM, A. Feijão. 2. ed. Viçosa, MG: UFV, 2006. p. 415-436.

RAMALHO, M. A. P.; FERREIRA, D. F.; OLIVEIRA, A. C. Experimentação em genética e melhoramento de plantas. 2. ed. Lavras: UFLA, 2005. 326 p.

RESENDE, O.; CORRÊA, P. C. Modelagem matemática do processo de hidratação de sementes de feijão. Acta Scintiarum Agronomy, Maringá, v. 29, n. 3, p. 373-378, 2007.

RESENDE, O.; CORREAA, P. C.; FARONI, L. R. D. A.; CECON, P. R. Avaliação da qualidade tecnológica do feijão durante o armazenamento. Ciência $e$ Agrotecnologia, Lavras, v. 32, n. 2, p. 517-524, 2008.

RESIO, A. N. C.; AGUERRE, R. J.; SUAREZ, C. Analysis of simultaneous water absorption and waterstarch reaction during soaking of amaranth grain. Journal of Food Engineering, London, v. 68, n. 2, p. 265- 270, may 2005.
Study of some factors affecting water absorption by amaranth grain during soaking. Journal of Food Engineering, London, v. 60, n. 4, p. 391-396, dec. 2003.

RIOS, A. O.; ABREU, C. M. P.; CORRÊA, A. D. Efeito da estocagem e das condições de colheita sobre algumas propriedades físicas, químicas e nutricionais de três cultivares de feijão (Phaseolus vulgaris L.). Ciência e Tecnologia de Alimentos, Campinas, v. 23, p. 39-45, 2003. Suplemento.

RODRIGUES, J. A.; RIBEIRO, N. D.; FILHO, A. C.; TRENTINI, M.; LONDERO, P. M. G. Qualidade para o cozimento de grãos de feijão obtidos em diferentes épocas de semeadura. Bragantia, Campinas, v. 64, n. 3, p. 369-376, 2005b.

RODRIGUES, J. A.; RIBEIRO, N. D.; LONDERO, P. M. G.; FILHO, A. C.; GARCIA, D. C. Correlação entre absorção de água e tempo de cozimento de cultivares de feijão. Ciência Rural, Santa Maria, v. 35, n. 1, p. 209213, jan./fev. 2005a.

SARTORI, M. R. Technological quality of dry beans (Phaseolus vulgaris) stored under nitrogen. 1982. PhD. (Dissertation) - Department of Grain Science and Industry. Kansas State University. Manhattan, Kansas, USA.

STANLEY, D. W.; AGUILERA, J. M. A review of textural defects in cooked reconstituted legumes - the influence of structure and composition. Journal of Food Biochemistry, Westport, v. 9, n. 4, p. 277-290, dec. 1985.

TEIXEIRA, I. R. BORÉM, A.; ARAÚJO, G. A. de A.; ANDRADE; M. J. B. de. Teores de nutrientes e qualidade fisiológica de sementes de feijão em resposta à adubação foliar com zinco e manganês. Bragantia, Campinas, v. 64, n. 1, p. 83-88, 2005.

VIEIRA, R. D. Teste de condutividade elétrica. In: VIEIRA, R. D.; CARVALHO, N. M. Testes de vigor em sementes. Jaboticabal: FUNEP, 1994. p. 103-132.

WASSIMI, N. N.; HOSFIELD, G. L.; UEBERSAX, M. A. Combining ability of tannin content and protein characteristics of raw and cooked dry beans. Crop Science, Madison, v. 28, n. 3, p. 452-458, 1988. 